\title{
Normal levels of anticoagulant heparan sulfate are not essential for normal hemostasis
}

\author{
Sassan HajMohammadi, ${ }^{1}$ Keiichi Enjyoji, ${ }^{2}$ Marc Princivalle, ${ }^{3,4}$ Patricia Christi, ${ }^{2}$ \\ Miroslav Lech, ${ }^{2}$ David Beeler, ${ }^{2}$ Helen Rayburn, ${ }^{2}$ John J. Schwartz, ${ }^{2}$ Samad Barzegar, ${ }^{5}$ \\ Ariane I. de Agostini, ${ }^{3}$ Mark J. Post,,${ }^{1,6}$ Robert D. Rosenberg, ${ }^{2,5}$ and Nicholas W. Shworak ${ }^{1}$
}

${ }^{1}$ Section of Cardiology, Department of Medicine, Dartmouth Medical School, Hanover, New Hampshire, USA ${ }^{2}$ Department of Biology, Massachusetts Institute of Technology, Cambridge, Massachusetts, USA

${ }^{3}$ Infertility Clinic, Department of Gynaecology and Obstetrics, Geneva University Hospital, Geneva, Switzerland ${ }^{4}$ Fondation pour Recherches Médicales, University of Geneva, Geneva, Switzerland

${ }^{5}$ Department of Medicine, Harvard Medical School, Beth Israel Deaconess Medical Center, Boston, Massachusetts, USA

${ }^{6}$ Department of Physiology, Dartmouth Medical School, Hanover, New Hampshire, USA

Endothelial cell production of anticoagulant heparan sulfate (HS $\left.{ }^{\text {act }}\right)$ is controlled by the Hs3st 1 gene, which encodes the rate-limiting enzyme heparan sulfate 3-O-sulfotransferase-1 (3-OST-1). In vitro, HS act dramatically enhances the neutralization of coagulation proteases by antithrombin. The in vivo role of $\mathrm{HS}^{\text {act }}$ was evaluated by generating $H s 3 s t 1^{-/-}$knockout mice. $H s 3 s t 1^{-/-}$animals were devoid of 3-OST-1 enzyme activity in plasma and tissue extracts. Nulls showed dramatic reductions in tissue levels of $\mathrm{HS}^{\text {act }}$ but maintained wild-type levels of tissue fibrin accumulation under both normoxic and hypoxic conditions. Given that vascular HS act predominantly occurs in the subendothelial matrix, mice were subjected to a carotid artery injury assay in which ferric chloride administration induces de-endothelialization and occlusive thrombosis. $H s 3 s t 1^{-/-}$and $H s 3 s t 1^{+/+}$mice yielded indistinguishable occlusion times and comparable levels of thrombin antithrombin complexes. Thus, $H s 3 s t 1^{-/-}$mice did not show an obvious procoagulant phenotype. Instead, $H s 3 s t 1^{-/-}$mice exhibited genetic background-specific lethality and intrauterine growth retardation, without evidence of a gross coagulopathy. Our results demonstrate that the 3-OST-1 enzyme produces the majority of tissue HSact. Surprisingly, this bulk of HS act is not essential for normal hemostasis in mice. Instead, 3-OST-1-deficient mice exhibited unanticipated phenotypes suggesting that $\mathrm{HS}^{\text {act }}$ or additional 3-OST-1-derived structures may serve alternate biologic roles.

J. Clin. Invest. 111:989-999 (2003). doi:10.1172/JCI200315809.

\section{Introduction}

Hemostatic tone is dynamically established as the net balance between ongoing procoagulant versus anticoagulant and fibrinolytic processes. Antithrombin (AT) is a major anticoagulant that slowly neutralizes proteases of the coagulation cascade through the formation of 1:1 enzyme AT complexes. The rate of neutral-

Received for publication April 26, 2002, and accepted in revised form January 7, 2003

Address correspondence to: Nicholas W. Shworak, Angiogenesis Research Center, HB7504, Dartmouth-Hitchcock Medical Center, Borwell Building 540W, One Medical Center Drive, Lebanon, New Hampshire 03756, USA. Phone: (603) 650-6401; Fax: (603) 653-0510; E-mail: nicholas.shworak@dartmouth.edu. Sassan HajMohammadi and Keiichi Enjyoji contributed equally to this work.

Conflict of interest: The authors have declared that no conflict of interest exists.

Nonstandard abbreviations used: antithrombin (AT); heparan sulfate (HS); HS proteoglycan (HSPG); thrombin (T); anticoagulant HS (HS $\left.{ }^{\text {act }}\right)$; nonanticoagulant HS (HS $\left.{ }^{\text {inact }}\right)$; HS 3-O-sulfotransferase-1 (3-OST-1); embryonic days after conception (E); adenosine $3^{\prime}$-phosphate $5^{\prime}$-phosphosulfate (PAPS); heparin cofactor II (HCII); cardiac microvascular endothelial (CME); alkaline phosphatase (AP); postnatal day (P); intrauterine growth retardation (IUGR). ization is dramatically enhanced by heparin, a variant of heparan sulfate (HS) from mast cells. Damus et al. (1) hypothesized that HS proteoglycans (HSPGs) on the endothelial cell surface might similarly accelerate AT activity and thereby contribute to the nonthrombogenic properties of blood vessels. Indeed, the perfusion of purified thrombin $(\mathrm{T})$ and AT into the hindlimbs of rodents led to an elevated rate of T $\bullet A T$-complex formation that was HS dependent. Endothelial cells produce only a small subpopulation of anticoagulant HS (HSact) that binds AT and accelerates in vitro T $\bullet$ AT complex generation (reviewed in refs. 2 and 3 ). This property distinguishes $\mathrm{HS}^{\text {act }}$ from the bulk of nonanticoagulent HS (HS $\left.{ }^{\text {inact }}\right)$, which lacks in vitro anticoagulant activity. It is presently unclear, however, whether $\mathrm{HS}^{\text {act }}$ is a major physiologic modulator of hemostasis.

For major hemostatic regulators, changes in the activity level can result in a hypercoagulable state (reviewed in refs. 3-5). For example, mutations that reduce the level of AT activity primarily predispose patients to venous thrombosis. Complete AT deficiency appears incompatible with human life and in mice causes intrauterine death from an extreme hypercoagulable state, consumptive coagulopathy $(6,7)$. Yet, the 
contribution of HSact deficiency toward human hypercoagulable states is unknown.

Conceivably, the level of $\mathrm{HS}^{\text {act }}$ produced by endothelial cells might tightly regulate hemostatic tone by controlling the enhancement of AT activity. Indeed, the plasma AT concentration $(2-5 \mu \mathrm{M})$ greatly exceeds the dissociation constant of AT for HS act $(\sim 15 \mathrm{nM})(8)$. So a small fraction of AT might always be bound to HSact and thereby exert a basal anticoagulant tone. Furthermore, endothelial cells can selectively regulate $\mathrm{HS}^{\mathrm{act}}$ levels, independent of $H S^{\text {inact }}(9,10)$, which could in turn modulate AT activity. HSact function may be important throughout the vascular tree, because patients that express AT variants with reduced affinity for heparin (type II heparin binding site) develop both venous and arterial thrombosis $(3,6)$. Typically, thrombosis occurs only if both AT genes are affected. Heterozygotes remain protected, which further supports that only a subfraction of normal AT is required for HS act function. Finally, a critical role for HS act is suggested by knockin mice that exclusively express a type II heparin binding site mutant of AT and spontaneously die throughout the first year of life, apparently from gross thrombosis (11).

The above examples, however, do not conclusively establish a critical role for HSact, because AT neutralization of $\mathrm{T}$ can also be enhanced by thrombomodulin bearing a chondroitin sulfate chain $(12,13)$. Moreover, the probing of blood vessels with ${ }^{125}$ I-AT reveals more than $95 \%$ of HS $^{\text {act }}$ are localized to the abluminal endothelial surface (14). Endogenous AT is bound to abluminal HS act (15); however, the lack of direct blood contact challenges the functional significance. To assess the importance of HS act toward AT-driven anticoagulation, we have sought to determine whether hemostatic tone is influenced by HS ${ }^{\text {act }}$ levels.

Modulation of HSact levels requires knowledge of $\mathrm{HS}^{\text {act }}$ structure and biogenesis. HS and heparin are functionally diverse biopolymers that occur on specific core proteins as a repeated disaccharide unit ( $N$-acetylglucosamine $\alpha 1 \rightarrow 4$ hexuronic acid $\beta 1 \rightarrow 4$ ) that is partially decorated with $N$ - and $O$-sulfate groups. In large part, the specific arrangement of these substituents gives rise to distinct binding motifs that activate an array of important biologic effector molecules. Such structures arise through remodeling of the copolymer backbone by a relatively ordered series of reactions involving four families of sulfotransferases (reviewed in refs. 16 and 17). For AT, the minimum binding domain generated in $\mathrm{HS}^{\text {act }}$ and heparin is the pentasaccharide: $\rightarrow \mathrm{N}$-acetylglucosamine 6-O-sulfate $\rightarrow$ glucuronic acid $\rightarrow$ glucosamine $\mathrm{N}$-sulfate 3 - $\mathrm{O}$-sulfate \pm 6 -O-sulfate $\rightarrow$ iduronic acid 2-O-sulfate $\rightarrow$ glucosamine $\mathrm{N}$-sulfate 6-Osulfate $\rightarrow$. AT forms specific contacts with several moieties; however, the central 3-O-sulfate group is absolutely essential for both high-affinity binding and enhancement of AT activity (2). Intriguingly, 3-O-sulfates are the rarest of HS modifications, typically comprising less than $0.5 \%$ of total sulfate moieties $(9,10)$, suggesting a potential regulatory role.
The regulation of HSact production has been elucidated over the past decade. Core proteins appear to exert minimal influence, because a single core can bear either HS act or HS inact (9). Instead, HS ${ }^{\text {act }}$ results from a discrete biosynthetic pathway regulated by a limiting biosynthetic factor $(9,10)$. Establishment of conditions for cell-free synthesis of $\mathrm{HS}^{\text {act }}$ revealed a limiting activity that modifies only a portion of potential precursors, thereby defining cellular production of HSact (18). The critical enzyme was purified, cloned, and identified as the long-sought heparan sulfate 3-O-sulfotransferase-1 (3-OST-1) $(19,20)$, which preferentially modifies selected HS structures to create the above pentasaccharide. It also creates a limited range of 3-O-sulfated structures that do not bind AT (21), but the biologic relevance of these structures is unknown. To date, 3-OST-1 has only been implicated in regulating hemostatic tone. Four additional 3-OST isoforms have been isolated, but these isoforms have dramatically distinct substrate preferences; therefore, they may regulate distinct biologic properties of HS (22-24). Some of these isoforms can generate HSact, but at about 250 -fold lower efficiency than 3-OST-1 (25). Thus, 3-OST-1 appears to be the dominant isoform regulating in vivo HSact production. Moreover, selective regulation stems from the enzymatic specificity of 3-OST-1 and the paucity of 3-O-sulfates within $\mathrm{HS}$.

Here, we investigated whether HSact levels influence hemostatic balance by generating $H s 3 s t 1^{-/-}$mice that are deficient in 3-OST-1 enzyme and show large reductions in $\mathrm{HS}^{\text {act }}$.

\section{Methods}

\section{Generation of $H s 3 s t 1^{-/-}$mice}

Isolation of the Hs3st1 coding region. An arrayed P1 library of 129P2/OlaHsd genomic DNA was PCR screened (Genome Systems Inc., St. Louis, Missouri, USA) with two different oligonucleotide sets designed to amplify $5^{\prime}$ and $3^{\prime}$ untranslated region sequences. Primers $5^{\prime}$ dATTGGCAACTGGAGATACTCATGT and 5'-dTGCCTTCTCCGGTGTCCTCT amplify nucleotides 219-467, whereas 5'-dTTCTGTACAGTATTAGATTCACAGT with 5'dGCTATTTTGGATTGGAGGCAGGT amplify nucleotides 1383-1617 from the mouse 3-OST-1 cDNA sequence (20). Three independent overlapping genomic clones were recovered, exons were mapped by Southern blotting, and the coding region was verified by DNA sequencing. This analysis revealed that exon 8 contained the entire coding region. A detailed description of this gene shall be presented elsewhere.

Gene targeting. A targeting vector (Figure 1a) was constructed from pMCIDT-A (a gift from Helene Baribault, Burnham Institute, La Jolla, California, USA) and designed to replace a $2.5-\mathrm{kb}$ genomic region (SpeI/BglI) encompassing the $H s 3 s t 1$ coding region with a $1.8-\mathrm{kb}$ (XhoI/Bam HI) neor expression cassette from pPNT. The $5^{\prime}$ targeting sequence was a $2.3-\mathrm{kb} S p h \mathrm{I} /$ SpeI fragment and the $3^{\prime}$ region was a $4.8-\mathrm{kb} B g l \mathrm{l} / \mathrm{Sph} \mathrm{I}$ fragment. 
Targeted D3 ES cells were generated and injected into C57BL/ 6 blastocysts as described previously (26).

Genotyping. Initially, genotyping was conducted by Southern blot analysis. Bam HI-digested genomic DNA from ES cell clones or mouse tails was hybridized to external probes generated by PCR of cloned genomic sequences. A 120 -bp $5^{\prime}$ probe was obtained with $5^{\prime}$ dGGATCCCTCGCCTGGTCTTAC and 5'-dTCTAGAAGTCAAATATACACAGAGT, whereas a 521-bp 3' probe was amplified with $5^{\prime}$-dCTCCTGAGTCACCTACACTGAG and 5'dGGATCCAGGACTAACTGACTTTT. Subsequently, genotyping was conducted by heteroduplex PCR. The wild-type allele generates a 235 -bp fragment with $5^{\prime}$ dTTCTGTACAGTATTAGATTCACAGT and 5'-dGCTATTTTGGATTGGAGGCAGGT, whereas, the knockout allele produces a 380 -bp product with $5^{\prime}$-dGCCAGCGGGGCTGCTAAA and 5'-dGCAGAGATGAGTTCCGCTTAC.

Breeding 3-OST-1-deficient mice. Chimeras were bred to C57BL/6 mice, and heterozygous progeny were interbred to create $\mathrm{F}_{2}$ individuals of approximately 50:50 mixed genetic background, which were used for all characterizations unless stated otherwise. Chimeras were also bred to $129 \mathrm{~S} 4 /$ SvJae mice to place the knockout allele on an incipient congenic background. The $H s 3 s t 1^{+/-}$129S4/SvJae mice were maintained through backcrossing as the $\mathrm{Hs}_{3} \mathrm{st} \mathrm{1}^{-/}$- genotype exhibited partial lethality $(\sim 40 \%)$ in this strain.

Analysis of perinatal mice. Noon on the day of vaginal plug appearance was defined as 0.5 embryonic days after conception (E0.5). Females were sacrificed on E18.5, and embryos were isolated with placentae attached. Neonates were harvested on the day of or 1 day after birth. Tail tissue, approximately $3 \mathrm{~mm}$, was harvested for genotyping. Perinatals were incubated in Bouin's solution for $48 \mathrm{~h}$, then washed in several changes of $70 \%$ ethanol over 3 weeks. Placentae were removed, and disks comprised solely of labyrinth and spongiotrophoblast layers were isolated from umbilical cords and membranes and then weighed. Fixation reduced embryo mass by approximately $14 \%$, irrespective of genotype. Biparietal diameter was measured with a digital caliper. Perinatal anatomy was assessed from crown-to-rump serial cross sections taken every 100-300 $\mu \mathrm{m}$.

\section{Characterization of 3-OST-1-deficient mice}

Experimental groups and statistical analysis. All experimental animals were generated from $\mathrm{Hs} 3 s t 1^{+/-} \times \mathrm{Hs}_{s} s t 1^{+/-}$ crosses. Experimental groupings employed age- and sex-matched littermates. Unless otherwise indicated, all data are expressed as the mean \pm SEM, and statistical significance was evaluated by two-tailed Student $t$ test.

Collection of plasma. For analysis of $\mathrm{T} \bullet \mathrm{AT}$ complexes, immediately after arterial injury a 0.5 -cc syringe containing $30 \mu \mathrm{l}$ of $3.8 \%$ trisodium citrate was used to draw approximately $300 \mu \mathrm{l}$ blood by a single puncture of the left ventricle. Otherwise approximately $170 \mu \mathrm{l}$ of blood was collected during tail tissue collection in tubes containing $10 \mu \mathrm{l}$ of $3.8 \%$ trisodium citrate. Plas- ma was prepared by two sequential centrifugations, then frozen on liquid $\mathrm{N}_{2}$ and stored at $-80^{\circ} \mathrm{C}$. For determination of 3-OST-1 activity, $70 \mu \mathrm{l}$ of fresh plasma was combined with $0.91 \mu \mathrm{l} \mathrm{of} 77 \mu \mathrm{g} / \mathrm{ml}$ pepstatin, $770 \mu \mathrm{g} / \mathrm{ml}$ leupeptin, $150 \mu \mathrm{g} / \mathrm{ml}$ aprotinin (SigmaAldrich, St. Louis, Missouri, USA), and $77 \mathrm{mM}$ Pefabloc SC (Boehringer Mannheim Biochemicals Inc., Indianapolis, Indiana, USA), then frozen.

Isolation of tissue homogenates and tissue HS. Mice were anesthetized with Avertin, then PBS was perfused into the left ventricle and blood was drained from the right jugular vein until clear. Organs were weighed, frozen in liquid $\mathrm{N}_{2}$, then ground with a polytron at $25,000 \mathrm{rpm}$ for $3 \mathrm{~min}$ in $2 \mathrm{ml}$ of $25 \mathrm{mM}$ ice-chilled 4-morpholineethanesulfonic acid, pH 6.5, $250 \mathrm{mM}$ sucrose, $1 \%$ Triton with $26 \mu \mathrm{l}$ of the above protease inhibitor mix. For tissue homogenates, a $0.3-\mathrm{ml}$ portion was centrifuged at $10,000 \mathrm{~g}$ for $1 \mathrm{~h}$ at $4^{\circ} \mathrm{C}, 200 \mu \mathrm{l}$ of clear supernatant was collected, protein concentration was determined by Bradford (27) with BSA as standard, then homogenates were frozen on liquid $\mathrm{N}_{2}$ and stored at $-80^{\circ} \mathrm{C}$. The remaining approximately $1.6 \mathrm{ml}$ of extract was sonicated five time for $3 \mathrm{~s}$, then $10^{6} \mathrm{cpm}$ of tracer $\left.{ }^{35} \mathrm{~S}\right] \mathrm{HS}$ was added to correct for extraction losses. Glycosaminoglycans were cleaved from proteoglycans by addition of $36 \mu \mathrm{l}$ of $5.6 \mathrm{M} \mathrm{NaOH}$ with $4.4 \mathrm{M}$ sodium borohydride and refluxed at $46^{\circ} \mathrm{C}$ for $12 \mathrm{~h}$. After centrifugation at $10,000 \mathrm{~g}$ for $20 \mathrm{~min}$, ice-chilled supernatants were slowly added to $0.5 \mathrm{ml}$ of $8.54 \mathrm{M}$ ammonium formate containing $1.7 \mathrm{M} \mathrm{HCl}$ in a vortexed 15 -ml tube. After centrifugation at $10,000 \mathrm{~g}$, supernatants were extracted four times against $5 \mathrm{ml}$ of phenol, three times against $7 \mathrm{ml}$ of phenol/chloroform/isoamyl alcohol (25:24:1), and once each against $3 \mathrm{ml}$ of chloroform/isoamyl alcohol (24:1) and $6 \mathrm{ml}$ isobutanol. Glycosaminoglycans were precipitated with $5 \mathrm{ml}$ ethanol, then harvested by centrifugation at $10,000 \mathrm{~g}$ for $1.5 \mathrm{~h}$. Pellets were resuspended in $100 \mu \mathrm{l}$ water, and chondroitin sulfate was degraded with 0.02 U of chondroitinase ABC (18). HS was purified by phenol extraction and ethanol precipitation (18), then mass was determined by forming complexes with Alcian blue (Fluka Chemical Corp., Milwaukee, Wisconsin, USA) (28) using kidney HS (ICN Biomedicals Inc., Costa Mesa, California, USA) as standard. Complexes were harvested by centrifugation at $10,000 \mathrm{~g}$ for $30 \mathrm{~min}$, then resuspended in $100 \mu \mathrm{l}$ of $8 \mathrm{M}$ guanidine $\mathrm{HCl}$ with $0.1 \%$ Triton $\mathrm{X}-100$ and spectrophotometrically measured at $\mathrm{A}_{600}$.

$H S^{\text {act }}$ conversion assay. The $\mathrm{HS}^{\text {act }}$ conversion assay (18) measures 3-OST-1 formation of AT-binding sites. In the presence of adenosine $3^{\prime}$-phosphate $5^{\prime}$-phosphosulfate (PAPS), 3-OST- 1 converts [ $\left.{ }^{35} \mathrm{~S}\right] \mathrm{HS}$, lacking 3-O-sulfates, into $\left[{ }^{35} \mathrm{~S}\right] \mathrm{HS}^{\text {act }}$, which contains AT-binding sites and is quantified by AT-affinity chromatography (9). $\left[{ }^{35} \mathrm{~S}\right] \mathrm{HS}$ lacking 3-O-sulfates was prepared from metabolically labeled CHO-K1 cells, and reactions containing 80,000 cpm of $\left[{ }^{35} \mathrm{~S}\right] \mathrm{HS}$ were assembled per Yabe et al. (25), with the following modifications to optimize sensitivity. 
Plasma $(1 \mu \mathrm{l})$ or lung homogenates $(20 \mu \mathrm{g})$ were analyzed in reactions containing $0.4 \mathrm{mg} / \mathrm{ml}$ chondroitin sulfate $\mathrm{C}$ and lacking $\mathrm{NaCl}$ and glycogen. Reactions for brain $(10 \mu \mathrm{g})$ or heart $(40 \mu \mathrm{g})$ homogenates lacked chondroitin sulfate, $\mathrm{NaCl}$, and glycogen. Activity was calibrated against purified recombinant 3-OST-1 standards, which were run in the absence and presence of plasma and tissue homogenates.

Measurement of anti-Xa activity of tissue $H S$, plasma AT activity, and plasma $T \bullet A T$ complexes. The in vitro activity of tissue HS to enhance AT neutralization of factor Xa was determined as described previously using S-2765 to monitor Xa activity (29). Activity was calibrated against a standard curve of porcine heparin (179 USP $\mathrm{U} / \mathrm{mg}$ ) (H-3393; Sigma-Aldrich). Plasma heparin cofactor II (HCII) activity was similarly detected using 205 $\mathrm{nM}$ human HCII with $125 \mathrm{nM}$ human $\alpha$-thrombin (Haematologic Technologies Inc., Essex Junction, Vermont, USA) and substrate S-2238 (Diapharma Group, West Chester, Ohio, USA). Plasma AT activity (anti-Xa activity) was measured with a Coamatic AT (Chromogenix Instrumentation Laboratory S.p.A., Milan, Italy) kit according to the manufacturer's specifications and using purified AT (Cutter Laboratories, Berkeley, California, USA) as standard. Plasma T•AT level was measured with an enzyme immunoassay using the Enzygnost TAT micro kit (Dade Behring Inc., Deerfield, Illinois, USA).

Tissue AT-binding activity. Organs (10-mg portions) were extracted twice in $500 \mu \mathrm{l}$ of $50 \mathrm{mM}$ Tris-HCl buffer, $\mathrm{pH}$ 8.0, containing $8 \mathrm{M}$ urea, $10 \mathrm{mM}$ EDTA, 1 $\mathrm{mM}$ PMSF, and $1 \mathrm{M}$ DTT, in a Potter homogenizer at room temperature. The pooled extracts were clarified by centrifugation for $30 \mathrm{~min}$ at $10,000 \mathrm{~g}$, and the supernatants were filtered through a $0.22-\mu \mathrm{m}$ Millex GV filter. The protein concentration of tissue extracts was determined using the bicinchoninic acid reagent (Pierce Chemical Co., Rockford, Illinois, USA). Aliquots of the tissue extracts containing 2-20 $\mu \mathrm{g}$ proteins were loaded in triplicate onto nitrocellulose membrane using a dot-blot apparatus, and ${ }^{125}$ I-AT ligand-binding assay was performed as described (30).

In situ detection of AT-binding sites. Tissue isolation, generation of cryosections, incubation of sections with ${ }^{125}$ I-labeled AT and autoradiography were all performed as described previously (31). Specificity of AT binding to $\mathrm{HS}^{\mathrm{act}}$ was confirmed by competition with soluble sulfated polysaccharides and by preincubation with GAG lyases (31). Dark-field and phase-contrast images were recorded with a color CCD camera (SPOT model 1.3.0; Diagnostic Instruments, Sterling Heights, Michigan, USA) and manipulated with Adobe Photoshop 6.0 using identical exposure and manipulation settings for $H s 3 s t 1^{+/+}$and $H s 3 s t 1^{-/-}$samples.

Tissue fibrin levels. Urea-insoluble tissue extracts (containing cross-linked fibrin) were prepared, and fibrin was measured by Western blot analysis with a fibrin-specific Ab, NYB T2G1, as described previously (32). Subsets of mice were subjected to overnight hypoxia $\left(8 \% \mathrm{O}_{2}\right)$ to induce procoagulant changes in lung tissue, as described (33).

Acute carotid artery injury. $\mathrm{FeCl}_{3}$-induced arterial injury was performed similar to published procedures (34). Analyses of inbred mouse lines showed that injury responses were very different for C57BL/6 versus $129 \mathrm{~S} 4 / \mathrm{SvJae}$ strains and that $\mathrm{F}_{2}$ hybrids yielded mice with extremely variable responses. Given this dependency on genetic background, studies were conducted with incipient congenic 129S4/SvJae mice only. Mice (25-35 g) were anesthetized with $1.25 \%$ Avertin $(0.34$ $\mathrm{mg} / \mathrm{g}$ intraperitoneally), intubated, and ventilated (14 $\mu \mathrm{l} / \mathrm{g} ; 111 \mathrm{breaths} / \mathrm{min}$ ). The right and left common carotid arteries were exposed by blunt dissection. Miniature Doppler flow probes (0.5VB; Transonic Systems Inc., Ithaca, New York, USA) were positioned around the distal limit of each common carotid artery and blood flow in both arteries was recorded simultaneously. Ten minutes after probe placement, the left carotid artery was chemically injured by applying a $1.0 \times 0.6-\mathrm{mm}$ strip of filter paper soaked in $30 \% \mathrm{FeCl}_{3}$ to the proximal adventitial surface for $1 \mathrm{~min}$. The field was flushed with saline, and flow was monitored until complete occlusion occurred. The injury procedure was then repeated on the right common carotid. Flow was measured with a Transonic T206 meter using a 30-Hz filter, and data were acquired with WinDaq software (DATAQ Instruments, Akron, Ohio, USA). Fast Fourier transformation identified the point at which flow was undetectable. Occlusion times were not correlated to initial blood flow rates $\left(H s 3 s t 1^{+/+} r^{2}<0.001 ; H s 3 s t 1^{-/-}\right.$ $r^{2}=0.0314$ ), so data were not adjusted for initial flow. Injured arteries were collected in Bouin's fixative, and platelet-rich thrombi were confirmed with hematoxylin and eosin staining of paraffin sections.

\section{3-OST-1 overexpression}

Retroviral transduction. $\mathrm{CHO} 4 \mathrm{~B}$ is a clonal line expressing the ecotropic retrovirus receptor (35). Primary mouse cardiac microvascular endothelial (CME) cells were described previously (20). pRV-3OST1 contains a 1.6-kb (Bgl II/Xho I) 3-OST-1 fragment from pCMV3OST (20). pRV-AP contains a secreted alkaline phosphatase (AP) cDNA, a 1.7-kb BglII/HpaI fragment from pSEAP2-basic (CLONETECH Labs Inc., Palo Alto, California, USA). The cDNAs were inserted into pMIG (36) (courtesy of D. Baltimore, California Institute of Technology, Pasadena, California, USA) upstream of IRES-GFP. The resulting bicistronic message also produces green fluorescent protein. Ecotropic retroviral vectors were generated with Phoenix cells as described previously (35). Both cell types were transduced by two successive exposures at a MOI of 0.75 (9), yielding approximately $90 \%$ of cells expressing green fluorescent protein.

Analysis of transductants. Previously, we described methods for measuring 3-OST-1 mRNA expression (20), 3-OST-1 enzyme activity (18), and HS act synthetic rate $(9,18)$. For cell surface activation of AT, multiwell 
plates were inoculated at 50,000 cells per $1.9-\mathrm{cm}^{2}$ well. Assay background was determined with wells lacking cells. Two-day-old cultures were washed with PBS containing $5 \mathrm{mg} / \mathrm{ml} \mathrm{BSA}$ and $40 \mathrm{nM}$ human AT (Cutter Laboratories). Monolayers were incubated at room temperature for up to $1 \mathrm{~h}$ with $0.1 \mathrm{ml}$ of PBS containing $40 \mathrm{nM}$ AT and $5 \mathrm{nM}$ human $\alpha$-thrombin (Haematologic Technologies Inc.). At 10-min intervals, quadruplicate wells were evaluated for residual $\mathrm{T}$ activity by combining $65 \mu \mathrm{l}$ of sample with $25 \mu \mathrm{l}$ of $1.8 \mathrm{mM}$ $\mathrm{S}-2238$ (Diapharma Group) in PBS. After $10 \mathrm{~min}$ at room temperature, reactions were quenched with $65 \mu \mathrm{l}$ glacial acetic acid, and $\mathrm{A}_{405}$ was measured. Given the above pseudo-first-order conditions, exponential decay constants were determined and corrected for the initial AT concentration to provide apparent second-order rate constants $\left(k_{2}{ }^{*}\right)$ for T neutralization (37).

\section{Results}

Generation of Hs3st1-/- mice. To examine whether hemostatic tone is tightly controlled by HS act levels, we generated $H s 3 s t 1^{-/-}$mice. Characterization of the mouse $H s 3 s t 1$ gene revealed that the entire 3-OST-1 coding region was encompassed within exon 8 . To generate mice deficient in 3-OST-1 enzyme, ES cells were electroporated with a replacement vector that eliminates exon 8 (Figure 1a). Southern blot analyses of 534 G418resistant ES cell clones with a $3^{\prime}$ probe revealed two homologous recombinants. Verification with a $5^{\prime}$ probe, however, demonstrated only a single clone had undergone appropriate $5^{\prime}$ recombination. Only this clone was devoid of exon 8 , as revealed by a coding region probe. Further probing for the neomycin resistance gene showed that this clone was devoid of extraneous integrations. Injection of this clone into blastocysts generated chimeric mice that were germline competent. Chimeras were bred to C57BL/6J females, and interbreeding of heterozygotes resulted in viable mice (Figure 1b) with comparable recovery of nulls and the wild-types. Tissue homogenates and plasma were evaluated for 3-OST-1 activity by the HS act conversion assay, which measures formation of AT-binding sites within HS (Figure 1c). Consistent with the removal of the entire gene-coding region, enzymatic activity was virtually absent in all samples from $H s 3 s t 1^{-/-}$mice.

3-OST-1 is the predominate source of HSact. The effect of $H s 3 s t 1$ disruption on in vivo levels of HS ${ }^{\text {act }}$ was revealed by isolating HS from a variety of tissues. For each tissue examined, recovery of total HS was comparable between $H s 3 s t 1^{-/-}$and $H s 3 s t 1^{+/+}$mice (data not shown). Indeed, given the scarcity of 3-O-sulfates within $\operatorname{HS}(9,10)$, altered HS levels should not occur. For most $H s 3 s t 1^{-/}$tissues examined, the in vitro anti-Xa activity of HS was reduced by $75-98 \%$, as compared with $H s 3 s t 1^{+/+}$material (Figure 2a). Probing blots of immobilized tissue extracts with ${ }^{125}$ I-AT revealed AT-binding sites in $H_{s} 3 s_{1} 1^{-/}$mice were similarly reduced (data not shown). The extent of reduction closely correlated with tissueexpression levels of 3-OST-1 mRNA, which we have determined previously (22). The minor residual ATbinding sites and anti-Xa activity suggest other 3-OST isoforms can contribute to HSact production. For most tissues, however, 3-OST-1 is clearly the predominant isoform and produces the vast majority of AT-binding sites. Large reductions of HSact might modestly perturb plasma AT levels, given that $10-20 \%$ of total body AT is sequestered by vascular endothelial HS act (38). Removal of this compartment could produce a slight elevation in plasma AT. Consistent with a loss of vascular HS ${ }^{\text {act }}$, baseline plasma AT activity was marginally elevated, by approximately $15 \%\left(H s 3 s t 1^{+/+} 1.8 \pm 0.05 \mathrm{U} / \mathrm{ml}, n=12\right.$ versus $\left.H s 3 s t 1^{-/-} 2.0 \pm 0.12 \mathrm{U} / \mathrm{ml}, n=7 ; P<0.05\right)$. a

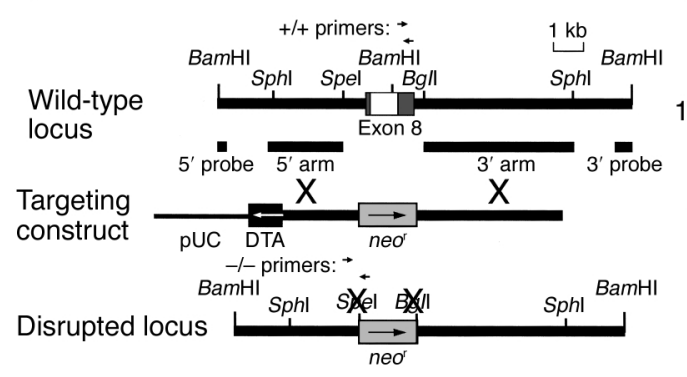

b

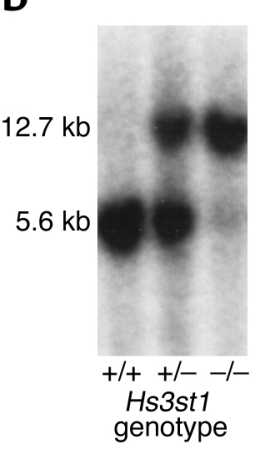

c

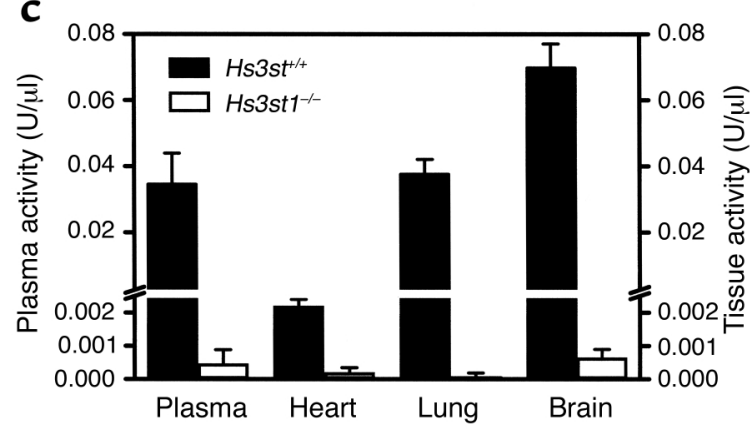

\section{Figure 1}

Disruption of the mouse Hs3st 1 locus. (a) Gene-targeting strategy. Exon 8 bridges two BamHI fragments and includes the entire coding sequence (white box) flanked by $5^{\prime}$ and $3^{\prime}$ noncoding sequences (dark gray boxes). The targeting construct replaces exon 8 with a neor expression cassette (light gray boxes) in the same transcriptional orientation. The disrupted locus lacks specific BamHI, Spel, and Bg/l sites. Restriction sites for producing targeting arms are shown. Also indicated are the locations of $5^{\prime}$ and $3^{\prime}$ probes for Southern blot analysis genotyping and primer sites for PCR analysis genotyping. (b) Genotyping by Southern blotting. Mouse tail genomic DNA was digested with BamHI, then the Hs3st 1 locus was detected with the external $5^{\prime}$ probe (shown in a). The wild-type allele generates a 5.6-kb band, whereas the disrupted allele generates a 12.7-kb band due to loss of a BamHI site. (c) 3-OST- 1 activity of mouse plasma and tissue homogenates; $n=3$ littermates per group. 3-OST-1 activity creates AT-binding sites within HS (producing HSact) and is determined by incubating tissue homogenate or plasma samples with $\left[{ }^{35} \mathrm{~S}\right] \mathrm{HS}$ and PAPS, then measuring the resultant $\left[{ }^{35} \mathrm{~S}\right] \mathrm{HS}$ act by AT-affinity chromatography. 

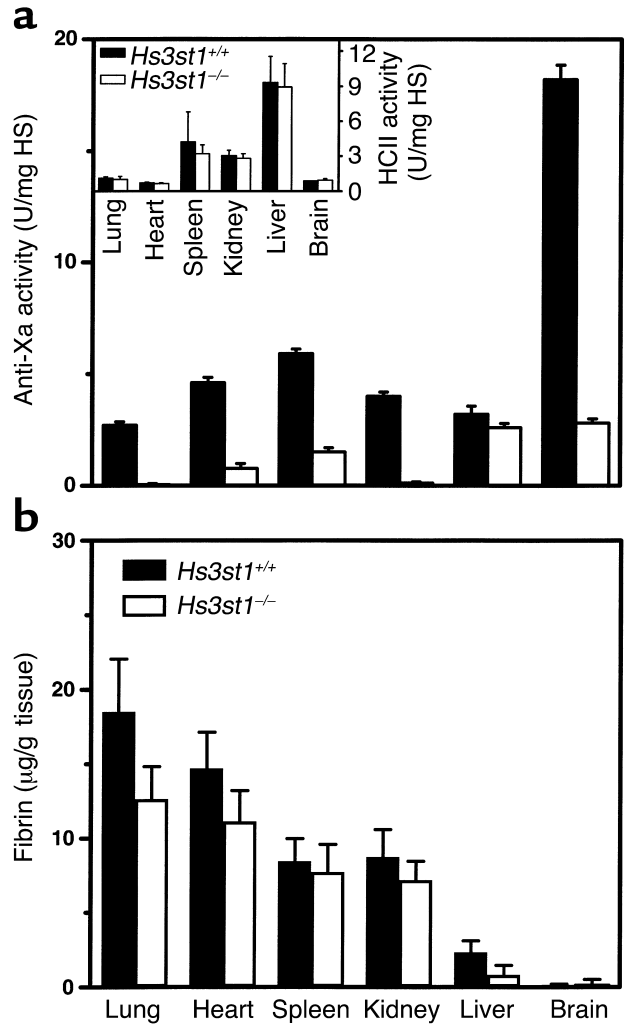

Hs3st $1^{-1-}$ mice do not show an obvious procoagulant phenotype. Given the large reductions in HS act, $H s 3 s t 1^{-/-}$were expected to show a procoagulant phenotype. We measured the basal accumulation of fibrin within tissues, which is an extremely sensitive index of microvascular hemostatic balance $(32,33)$. Surprisingly, tissue fibrin levels for $\mathrm{Hs} 3 \mathrm{st}^{-/-}$mice were indistinguishable from $\mathrm{Hs}_{3 \mathrm{st}} \mathrm{1}^{+/+}$littermates (Figure 2b). Wild-type fibrin accumulation even occurred in organs with extremely low residual levels of anti-Xa activity (e.g., $H s 3 s t 1^{-/-}$lung and kidney, which had reductions of $\sim 98 \%$, Figure $2 \mathrm{a}$ ). Thus, a basal procoagulant state was not detected.

In an attempt to uncover a latent procoagulant condition, mice were subjected to a procoagulant challenge - overnight hypoxia $\left(8 \% \mathrm{O}_{2}\right)$. Prolonged hypoxia elevates expression of tissue factor in the monocyte/macrophage lineage and in pulmonary vascular endothelial cells, which leads to enhanced fibrin accumulation and pulmonary thrombosis (33, 39). Despite the large $\mathrm{HS}^{\mathrm{act}}$ reduction in $\mathrm{Hs}_{3} \mathrm{st1} \mathrm{1}^{-/}$ lung, hypoxia-induced fibrin accumulation was comparably elevated ( 2.5 -fold) in lungs of control and 3-OST-1-deficient animals $\left(H s 3 s t 1^{+++} 38.4 \pm 4.0 \mu \mathrm{g} / \mathrm{g}\right.$ tissue versus $H s 3 s t 1^{-/-} 40.1 \pm 4.4 \mu \mathrm{g} / \mathrm{g}$ tissue; $n=10$ littermates per group). Thus, a thrombotic challenge also failed to reveal a microvascular procoagulant state in $H s 3 s t 1^{-/-}$mice.

We next focused on the macrovasculature, where large accumulations of HSact occur in the subendothelial matrix $(14,15)$. To confirm that 3-OST-1 deficiency affects macrovascular HS ${ }^{\text {act }}$, AT-binding

\section{Figure 2}

Hs3st1 disruption reduces tissue $\mathrm{HS}^{\text {act }}$ level but does not alter fibrin accumulation. (a) HSact content of HS purified from tissues was measured as in vitro anti-Xa activity, where HS containing AT-binding sites catalyzes AT neutralization of factor Xa. Inset shows the activity of tissue $\mathrm{HS}$ to catalyze $\mathrm{HCll}$ neutralization of T. Activities were calibrated to the USP units of a heparin standard; $n=3$ littermates per group. (b) Tissue fibrin accumulation was determined by first preparing ureainsoluble extracts, which selectively enriches for cross-linked fibrin. Fibrin was quantified by Western blots probed with a mAb specific to the cleaved $\beta$-chain of fibrin II. Each group contained five young adult mice and five middle-aged mice ( 10 or $\sim 24$ weeks of age, respectively) with no significant effect of age on fibrin accumulation.

sites were identified by probing carotid artery cryosections with ${ }^{125} \mathrm{I}-\mathrm{AT}$. Endothelial HS ${ }^{\text {act }}$ was abundant in $H s 3 s t 1^{+/+}$mice, but was almost undetectable in Hs3st1 $1^{-/}$littermates (Figure 3a). The loss of HSact might make $H s 3 s t 1^{-/-}$vessels prone to rapid thrombosis when the subendothelial matrix is exposed by endothelial injury. This hypothesis was tested by injuring common carotid arteries with a standardized adventitial application of $30 \% \mathrm{FeCl}_{3}$, which results in focal endothelial denudation and rapid development of an occlusive platelet-rich thrombus. This approach is a proven means of documenting accelerated arterial thrombosis $(34,40,41)$. Moreover, a comparable method has shown the anticoagulant activity of HCII is only manifest upon exposure of the subendothelial matrix (42). We empirically determined that $30 \%$ $\mathrm{FeCl}_{3}$ was the minimum dose required to initiate a

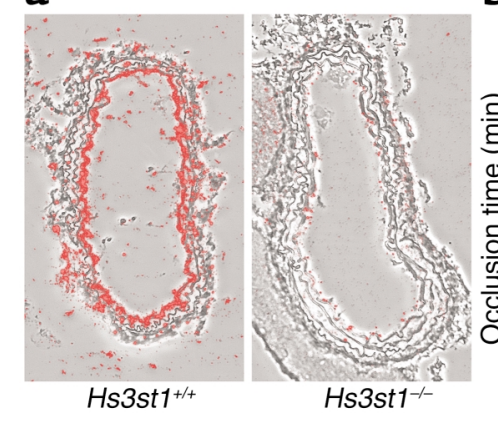

b

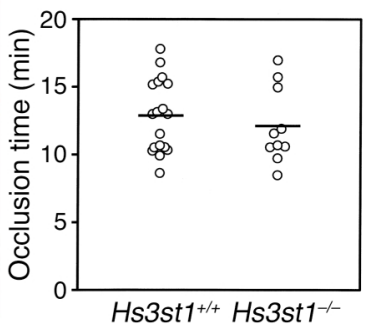

Figure 3

Hs3st 1 disruption reduces carotid artery AT-binding sites but does not alter thrombotic response to acute arterial injury. (a) AT-binding sites were visualized by incubating cryosections of carotid artery with ${ }^{125}$ I-AT followed by autoradiography. Silver grains were detected by dark-field microscopy, then digitally false-colored red. Resulting images were superimposed over corresponding phase-contrast images. (b) Acute endothelial injury was initiated by adventitial application of $\mathrm{FeCl}_{3}$ to a common carotid artery. Blood flow was monitored with extravascular micro-Doppler probes to detect the occlusion time from $\mathrm{FeCl}_{3}$ application to complete cessation of blood flow. Responses were sequentially obtained from the left and then the right carotid; vessel side did not affect occlusion time by ANOVA analysis. Each data point reflects a single vessel from $\mathrm{Hs}_{3 s t 1^{+/+}}(n=11)$ or $H_{s} 3 s t 1^{-1-}(n=6)$ littermates. Mean occlusion times were $12.7 \pm 0.6$ min for $\mathrm{Hs}_{s} \mathrm{st} \mathrm{1}^{+/+}$and $12.1 \pm 0.9 \mathrm{~min}$ for $\mathrm{Hs}_{\mathrm{s}} \mathrm{st} \mathrm{1}^{-/-}$mice. 
occlusive thrombosis, so should allow detection of enhanced thrombosis (data not shown). Thrombi that formed in wild-type and knockout mice were comparable by gross histologic inspection (results not shown). Monitoring blood flow revealed that the time to generate a complete occlusion was indistinguishable between genotypes (Figure $3 \mathrm{~b}, P>0.5$ ). A potential difference might be masked if lack of 3-O-sulfates enhances the HCII activity of HS. This possibility, however, was ruled out because the HCII activity of tissue HS was identical between genotypes (Figure 2a inset). Immediately after occlusion of both common carotid arteries, an intraventricular blood sample was drawn to measure $\mathrm{T} \bullet \mathrm{AT}$ complexes. The postinjury concentration of $\mathrm{T} \bullet \mathrm{AT}$ complexes within plasma was independent of mouse genotype $(9.1 \pm 1.2 \mu \mathrm{g} / \mathrm{l}$ versus $9.7 \pm 1.0 \mu \mathrm{g} / \mathrm{l}$ for $\mathrm{Hs}_{s} s t \mathrm{1}^{+/+}$and $\mathrm{Hs} 3 \mathrm{st} \mathrm{1}^{-/-}$, respectively; mice analyzed in Figure $3 \mathrm{~b}$ ). Thus, the profound reduction in subendothelial matrix $\mathrm{HS}^{\mathrm{act}}$ did not expedite occlusive thrombosis in $H s 3 s t 1^{1--}$ mice and did not alter postinjury levels of $\mathrm{T} \bullet \mathrm{AT}$ complexes in plasma. 3-OST-1 overexpression fails to enhance AT activation by the endothelial cell surface. As a complementary approach to assess the influence of HSact levels on coagulation, we overexpressed 3-OST-1 in primary mouse CME cells, which have endogenous 3-OST-1 expression (20), and in $\mathrm{CHO} 4 \mathrm{~B}$, a nonendothelial cell line lacking 3-OST-1 (43). Cells were transduced with the retroviral vector PRV-3OST1 or the control vector pRV-AP, which respectively express cDNAs for 3-OST-1 or a secreted form of AP. The pRV-3-OST-1 transductants, compared with PRV-AP transductants, showed increased 3-OST-1 mRNA and enzyme levels, as revealed by Northern blotting and HSact conversion assays, respectively (data not shown). We then measured cellular synthesis of HSact and ability of cell monolayers to enhance AT neutralization of $\alpha$-thrombin (Figure 4). For pRVAP transductants, $\mathrm{HS}^{\text {act }}$ production and $\alpha$-thrombin inactivation were only evident in cells with endogenous 3-OST-1 expression (CME as opposed to $\mathrm{CHO} 4 \mathrm{~B}$ cells). pRV-3OST1 transduction elevated HSact synthesis in both cell types $(P<0.001$, compared with pRV-AP transductants). Catalysis of AT activity, however, was only elevated for monolayers of CHO4B cells $(P<0.001)$, but not CME cells $(P>0.2)$. Although $\mathrm{HS}^{\text {act }}$ can contribute to cell surface activation of AT in $\mathrm{CHO} 4 \mathrm{~B}$, there does not appear to be a 1:1 correlation between HS act production and cell surface activity in CME cells. The lack of correlation might suggest that $\mathrm{HS}^{\mathrm{act}}$ is not the sole endothelial anticoagulant and/or that mechanisms exist to maintain a set anticoagulant tone on the endothelial surface. Regardless, these results are consistent with $H s 3 s t 1^{-/}$data showing HSact levels and anticoagulant state are not tightly linked.

$H s 3 s t 1^{-1-}$ mice have genetic background-dependent postnatal lethality. $\mathrm{Hs} 3 \mathrm{st} \mathrm{1}^{-/-}$mice are further remarkable because they develop several unanticipated abnormalities, including postnatal lethality and intrauterine growth retardation. Such phenotypes can arise from a gross coagulopathy $(7,44)$. Consequently, we examined whether perinatal traits of $\mathrm{Hs}_{3} \mathrm{st}^{-/-}$mice stem from such a cause. These phenotypes were detected while altering strain genetic background. Knockout mice were initially generated on a mixed genetic background (C57BL/6× 129S4/SvJae). The knockout allele was successively bred through C57BL/ 6 mice. After seven backcrosses, less than approximately $1 \%$ of the genome is derived from the original ES cell clone; thus, perinatal phenotypes are unlikely to have resulted from a secondary gene mutation. It remains conceivable that targeting of the $H s 3 s t 1$ locus has perturbed the expression of adjacent genes; thus, we can not yet conclusively prove direct causation from loss of 3-OST-1 expression. The potential involvement of a gross procoagulant state, however, obligated our evaluation of these phenotypes.

$H s 3 s t 1^{+/-}$mice from various backcrosses were interbred to produce litters on progressively enriched C57BL/6
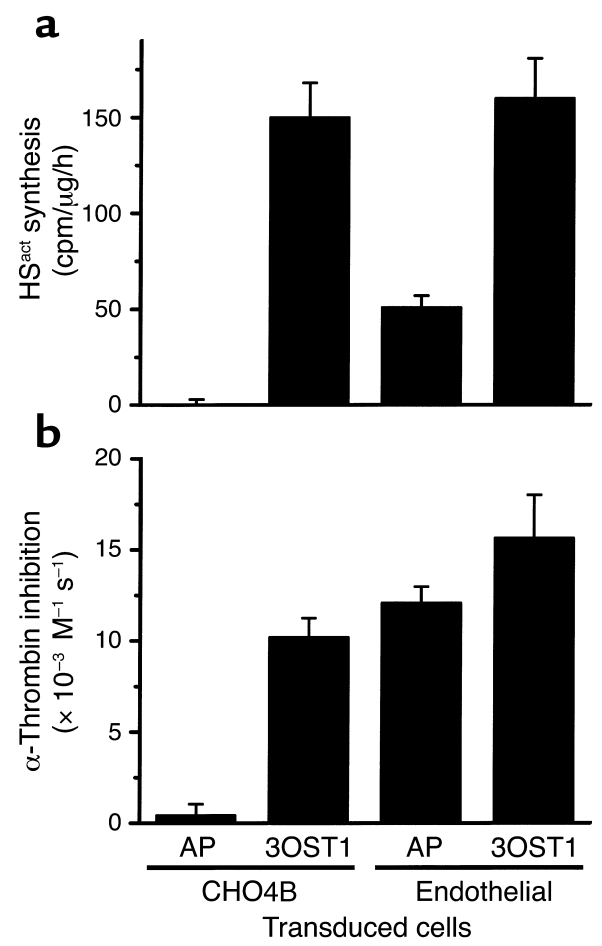

\section{Figure 4}

Overproduction of HSact in endothelial cells does not augment cell surface activation of AT. CME (Endothelial) and nonendothelial (CHO4B) cells were transduced with pRV-3OST1 (3OST1) or PRV-AP (AP) retroviral vectors. (a) $\mathrm{HS}^{\text {act }}$ synthesis was determined by pulse-labeling cells $1 \mathrm{~h}$ with [ $\left.{ }^{35} \mathrm{~S}\right] \mathrm{NaSO}_{4}$ followed by $\mathrm{HS}$ purification and AT-affinity chromatography ( $n=3$ independent labelings). Incorporation rate into $\mathrm{HS}^{\text {act }}$ is expressed as AT-bound [ $\left.{ }^{35} \mathrm{~S}\right] \mathrm{HS}$, standardized to cellular protein. (b) Cell surface catalysis of AT activity was determined by incubating monolayers with $\alpha$-thrombin and excess AT. At various times, residual $\alpha$-thrombin activity was chromogenically determined and apparent second-order rate constants $\left(k_{2}^{*}\right)$ for T inactivation were derived ( $n=4$ independent experiments). Monolayer-dependent catalysis was determined by subtracting the assay background of $3,800 \mathrm{M}^{-1} \mathrm{~s}^{-1}$ (obtained by incubations without monolayers). Comparable data were also obtained for AT neutralization of factor Xa (not shown). 

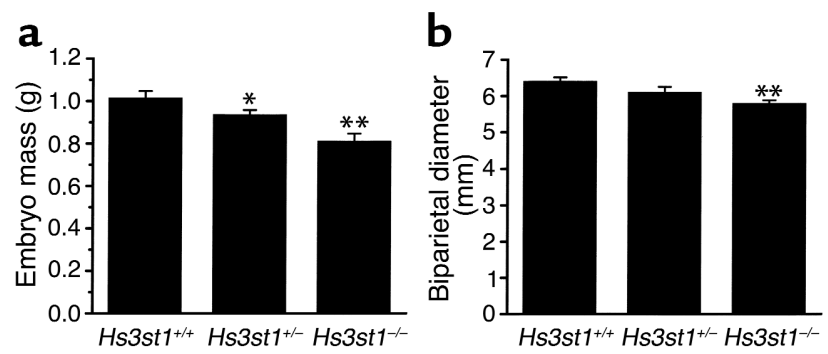

\section{Figure 5}

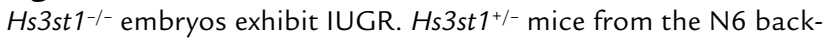
cross were interbred, and the resulting embryos harvested at E18.5 were fixed, as described in Methods. Embryo mass without placenta (a) and head diameter (b) were then measured. ${ }^{*} P<0.05$ and ${ }^{*} P<0.001$, compared with $\mathrm{Hs}_{3} \mathrm{st} \mathrm{1}^{+/+}$gestation mates. $n=10$ $\mathrm{Hs} 3 \mathrm{st}^{+/+}, 17 \mathrm{Hs} 3 \mathrm{st} \mathrm{1}^{+/-}$, and $12 \mathrm{Hs} 3 \mathrm{st} \mathrm{1}^{-/-}$embryos.

backgrounds. Surprisingly, the recovery of $H s 3 s t 1^{-/-}$ weanlings dramatically diminished as C57BL/ 6 content increased (a representative lineage presented in Table 1). After four backcrosses, recovery of $\mathrm{Hs}_{s} \mathrm{st}^{-/-}$weanlings bottomed out at approximately $10 \%$ of $H s 3 s t 1^{+/+}$levels (Table 1; compare N4 to N7). Hs3st1 ${ }^{+/-}$mice showed a partial effect with recovery being approximately $35 \%$ of expected (N4 + N7 litters had $30 \mathrm{Hs}_{s} s \mathrm{t}^{+/+}$, so should have produced $60 \mathrm{Hs} 3 \mathrm{st} \mathrm{1}^{+/-}$). $\mathrm{Hs} 3 \mathrm{st} \mathrm{1}^{-/-}$lethality persisted even when litters were produced by embryo transfer into the high-fecundity mouse strain FVB/N [Table 1; N7 (ET)]. Thus, lethality was predominantly dependent on offspring genotype rather than maternal genotype. The requirement for an enriched C57BL/ 6 background was further confirmed by breeding $H s 3 s t 1^{+/-}$mice from the eighth generation backcross (N8) to $H s 3 s t 1^{+/-}$mice produced on an incipient congenic 129S4/SvJae background. $H s 3 s t 1^{-/}$lethality was completely rescued by the resulting hybrid background.

AT-deficient $\left(A T I I I^{--}\right)$mice have intrauterine lethality with no survival past E16.5 (7). Given that a gross hypercoagulable state is causative, we examined if $H s 3 s t 1^{-/-}$lethality mimics AT deficiency; however, $H s 3 s t 1^{-/-}$mice showed normal viability 1 day before birth (E18.5) with only slight reductions within $48 \mathrm{~h}$ of delivery (Table 1; genotype analysis of P0/P1 at N6).
The lethality is probably complete by postnatal day $2-3$ (P2-P3) because reductions in litter size were frequently observed during this period (results not shown). Thus, in contrast to ATIII ${ }^{-/-}$mice, $H s 3 s t 1^{-/-}$mice exhibited postnatal rather than intrauterine lethality. In humans, AT deficiency and other hypercoagulable states can lead to postnatal lethality from purpura fulminans (6); however, bruising and subcutaneous hemorrhages were not evident in newborn $H s 3 s t 1^{-/-}$pups, despite being subjected to normal birth trauma. Furthermore, $H s 3 s t 1^{-/}$newborns had unlabored breathing, ingested milk, produced and excreted urine, and exhibited normal startle reflexes to noise and motion. Thus, a gross cause for postnatal lethality was not readily apparent. Histological surveys of E18.5 and P0 mice failed to reveal thrombosis, hemorrhage, or anatomical anomalies in $\mathrm{Hs}_{s} \mathrm{st}^{-{ }^{-}}$embryos. Most importantly, myocardial and hepatic tissues lacked focal thrombosis and degeneration (data not shown), which invariably occurs in late-stage $A T I I I^{-/-}$embryos (7). Thus, $H s 3 s t 1^{-/-}$lethality is distinct from $A T I I I^{-/-}$lethality.

Hs3st1 $1^{-/}$embryos show intrauterine growth retardation. Although anatomical malformations were not apparent, $H s 3 s t 1$ genotype did influence embryonic mass in a dose-dependent fashion. Compared with wild-type mice, $H s 3 s t 1^{+-}$and $H s 3 s t 1^{-/}$E18.5 embryos were $8 \%$ and $20 \%$ underweight, respectively (Figure 5a), and thus exhibited intrauterine growth retardation (IUGR). Although suckling reduces weight differences, growth retardation remained detectable in newborns (at P0, $H s 3 s t 1^{+/+}$were $1.26 \pm 0.02 \mathrm{~g}, n=12$, verses $1.14 \pm 0.04 \mathrm{~g}$ for $\left.H s 3 s t 1^{-/-}, n=7 ; P<0.01\right)$. Procoagulant states have been proposed to induce placental vascular insufficiency and thereby cause IUGR (45). Embryo/placental-disk ratios, however, which are typically elevated in placental insufficiency, were comparable between genotypes ( $H s 3 s t 1^{+/+}$and $H s 3 s t 1^{-/-}$ratios were $19.7 \pm 0.8$ versus 20.8 \pm 1.1 , respectively). IUGR from placental insufficiency also usually shows sparing of head growth (asymmetric IUGR) $(46,47)$. Yet $H s 3 s t 1^{-/-}$embryos, compared with $H s 3 s t 1^{+/+}$gestation mates, showed a significant reduction in the biparietal diameter (Figure 5b) - an established parameter of embryonic head growth (48).

Table 1

Genotypes of offspring from heterozygous parents $\left(H s 3 s t 1^{+/-} \times H s 3 s t 1^{+/-}\right)$

\begin{tabular}{|c|c|c|c|c|c|c|c|c|}
\hline \multirow[t]{2}{*}{ Parental background ${ }^{A}$} & \multirow{2}{*}{$\begin{array}{c}\text { Offspring C57BL/6 } \\
\text { content }\end{array}$} & \multicolumn{3}{|c|}{ Offspring Hs3st1 genotype } & \multirow{2}{*}{$\begin{array}{l}\text { +/+:-/- } \\
\text { ratio }\end{array}$} & \multirow{2}{*}{$\begin{array}{c}\text { Loss of } \\
H s 3 s t 1^{-/-B}\end{array}$} & \multirow[t]{2}{*}{$P C$} & \multirow[t]{2}{*}{$\mathrm{Age}^{\mathrm{D}}$} \\
\hline & & $+/+$ & $+/-$ & $-/-$ & & & & \\
\hline N1 & $\sim 50.0 \%$ & 35 & 106 & 35 & $1: 1$ & - & - & $\mathrm{P} 21$ \\
\hline N3 & $\sim 87.5 \%$ & 21 & 45 & 5 & $1: 0.24$ & $76 \%$ & $<0.003$ & P21 \\
\hline N4 & $\sim 93.8 \%$ & 16 & 13 & 1 & $1: 0.06$ & $94 \%$ & $<0.001$ & $\mathrm{P} 21$ \\
\hline N6 & $\sim 98.4 \%$ & 10 & 17 & 12 & $1: 1$ & - & - & E18.5 \\
\hline N6 & $\sim 98.4 \%$ & 18 & 26 & 11 & $1: 0.60$ & $39 \%$ & - & $\mathrm{P} 0+\mathrm{P}$ \\
\hline N7 (ET) & $\sim 99.2 \%$ & 14 & 8 & 2 & $1: 0.14$ & $86 \%$ & $<0.001$ & P14 \\
\hline $\mathrm{N} 8_{\text {male }} \times 129 \mathrm{~S} 4 / \mathrm{SVJae}$ female & $50.0 \%$ & 25 & 56 & 22 & $1: 1$ & - & - & $\mathrm{P} 21$ \\
\hline
\end{tabular}

AN indicates number of successive backcrosses to generate parental $H s 3 s t 1^{+/-}$. ET indicates litters were generated by embryo transfer into FVB/N females. ${ }^{\mathrm{B}}$ Loss expressed relative to $\mathrm{Hs} 3 s t 1^{+/+}$. CProbability of a non-Mendelian outcome determined by $\chi^{2}$ test. DAge at which tissue was collected for genotyping. P, postnatal day; E, embryonic days after conception. 
To assess whether reductions in head growth and embryonic mass were proportionate, we calculated a modified ponderal index (embryo mass $\div$ [biparietal diameter $]^{3}$ ). This index was indistinguishable between genotypes $\left(H s 3 s t 1^{+/+}, H s 3 s t 1^{+/-}\right.$, and $H s 3 s t 1^{-/-}$values were $3.9 \pm 0.20,4.0 \pm 0.19$, and $4.1 \pm 0.18 \mathrm{~g} / \mathrm{mm}^{3}$, respectively) indicating that $\mathrm{Hs}_{3} \mathrm{st} \mathrm{1}^{-/-}$mice exhibit symmetric IUGR. Thus, the IUGR of $H s 3 s t 1^{-/-}$embryos was not suggestive of placental vascular insufficiency. In a mouse model of thrombotic placental insufficiency that produces a comparable degree of IUGR (E18 embryos being 20\% underweight), placentae exhibit fibrin thrombi and congestion (49). However, $\mathrm{Hs}_{3 s t 1^{-/-}}$placentae were microscopically normal (data not shown). Nor was there evidence of giant cell hyperplasia, a feature of severe placental ischemia. Taken together, the data suggest the IUGR of $\mathrm{Hs}_{s} \mathrm{st} \mathrm{1}^{-/-}$mice did not stem from an overt procoagulant state. The contribution of IUGR toward neonatal lethality of $\mathrm{Hs}_{s} \mathrm{st} \mathrm{I}^{-/-}$mice warrants further investigation.

\section{Discussion}

To examine if hemostatic tone is tightly controlled by HS act levels, we generated $H s 3 s t 1^{-1-}$ mice. The lack of 3-OST-1 enzyme causes large reductions in HSact levels in most organs. Hs $3 s t 1^{-/-}$mice were evaluated by techniques capable of detecting altered hemostatic balance $(7,32-34,40,41)$. Despite removing the majority of HSact, basal fibrin levels were completely unaltered in 3-OST-1-deficient mice. Even after a strong procoagulant stimulus (hypoxic challenge), lung fibrin levels in knockout mice were indistinguishable from wild-type mice. These results are particularly surprising given the dynamic nature of hemostatic balance. However, most of HSact occurs in the subendothelial matrix. Consequently, an anticoagulant role might only be operable in the context of endothelial denudation, which would allow direct contact of the blood and matrix. But evaluation of $H s 3 s t 1^{-/-}$and $H s 3 s t 1^{+/+}$mice by an arterial injury model revealed both genotypes to have comparable vessel occlusion times and equivalent postinjury levels of T•AT complexes. Taken together, these analyses indicate that 3-OST-1-deficient mice lack an obvious procoagulant phenotype. Thus, hemostatic balance was not dependent on $\mathrm{HS}^{\text {act }}$ levels.

As a complementary approach, we employed 3-OST-1 overexpression to examine the effect of HSact production on cell surface catalysis of AT activity. Overexpression conveyed both properties to cells lacking endogenous 3-OST-1. In endothelial cells, however, 3-OST-1 overexpression failed to enhance the preexisting highcatalytic activity of the cell surface, despite augmenting HSact synthesis threefold. Again, anticoagulant activity was not tightly linked to HSact production levels. This lack of correlation is consistent with observations that $\mathrm{HS}^{\mathrm{act}}$ is not the sole endothelial component capable of catalyzing AT activity $(12,13)$.

Failure to detect a procoagulant phenotype in $\mathrm{Hs}_{3} \mathrm{st}^{-/-}$mice indicates HSact is not a major hemostat- ic regulator like AT, thrombomodulin, or fibrinolytics. With these potent regulators, even a heterozygotic deficiency leads to fibrin elevations/hypercoagulable state $(3,5,6)$. Our data, however, do not rule out some anticoagulant role for HS act. First, 3-OST-1-deficient mice maintain a small residual amount of $\mathrm{HS}^{\text {act }}$. Residual HS act is likely produced by other members of the 3-OST multigene family. For example, the liver has high residual HSact and high expression of $3-\mathrm{OST}-3_{\mathrm{A}}$ and $3-\mathrm{OST}-3_{\mathrm{B}}$. These isoforms, however, show low efficiency when generating HSact $(22,25)$. Conversely, we have recently identified the final gene family members, 3-OST-5 and 3-OST-6. The latter is most homologous to 3-OST-1 in both genomic organization and protein structure. Moreover, 3-OST-6 is nearly as efficient as 3-OST-1 in generating HS ${ }^{\text {act }}$ (Rhodes, HajMohammadi, Seeberger, McNeely, Spear, and Shworak, unpublished data). 3-OST-6 might play an important role if hemostatic balance requires only low levels of $\mathrm{HS}^{\text {act }}$. For example, HS act on the endothelial luminal surface is present in relatively minute amounts $(14,15)$, but such localization might be essential for anticoagulant activity. Due to assay-sensitivity limitations, it is presently unclear whether 3-OST-1 deficiency affects luminal HSact. Second, anticoagulant/fibrinolytic knockout mice show enhanced fibrin accumulation in a distinct spectrum of tissues $(26,32-34)$. The tissues examined in our present study have been sufficient to demonstrate a procoagulant state in such knockout mice. But potentially 3-OST-1-generated HSact might serve an anticoagulant role in only a minor tissue not yet examined. Third, compensatory mechanisms might have masked a hemodynamic perturbation. Unmasking of an overt procoagulant effect might require an additional genetic defect. For example, combining the deficiencies for thrombomodulin and tissue plasminogen activator leads to an extreme hypercoagulable state with myocardial necrosis and depressed cardiac function (32). We are presently evaluating the above possibilities.

Our results do not exclude HSact as a natural anticoagulant but instead suggest that the majority of $\mathrm{HS}^{\mathrm{act}}$ is not essential for normal hemostatic tone. If the murine situation reflects human physiology, then the large number of hypercoagulable patients with undefined etiology $(3,4)$ cannot be the result of a deficiency in just 3-OST-1. It remains conceivable, however, that human 3-OST-1 deficiency might exert an affect when combined with deficiencies for other 3-OST isozymes or other anticoagulants/fibrinolytics.

Instead of an anticipated procoagulant state, $H s 3 s t 1^{-/-}$mice exhibited unexpected phenotypes. Here we characterized two examples that do not appear to be of gross procoagulant origin. First, the $H s 3 s t 1^{-/-}$ mice showed genetic background-dependent lethality that is very distinct from the intrauterine lethality observed in $A T I I I^{-/-}$mice. Hs $3 s t 1^{-/-}$lethality occurred postnatally and was rescued on the mixed genetic background permissive for $A T I I I^{-/-}$lethality. Moreover, 
$H s 3 s t 1^{-/-}$embryos lack the gross and microscopic features of consumptive coagulopathy found in $\mathrm{ATIII}^{-/}$ embryos. Second, $\mathrm{Hs}_{s} \mathrm{st} \mathrm{1}^{-/}$embryos had IUGR. IUGR has been associated with placental insufficiency induced by procoagulant states, albeit typically of maternal origin $(45,50)$. Hs $3 s t 1^{-1-}$ embryos, however, did not exhibit features of placental vascular insufficiency. Moreover, Hs3st1 $1^{-/}$placentae lacked microscopic evidence of thrombotic vascular insufficiency. Lethality might be secondary to IUGR, because lactating mice can preferentially kill low-birth weight infants during the first week of life (51). Intriguingly, IUGR and lethality are both less severe for $\mathrm{Hs}_{3} s \mathrm{1}^{+/-}$ than $H s 3 s t 1^{-/-}$mice, which would be consistent with the above method of litter "quality control." Regardless, both lethality and IUGR of Hs3st1 $1^{-/-}$mice did not appear to result from a gross procoagulant state. Potentially, these phenotypes might reflect a novel activity of HSact or of other 3-OST-1-generated structures. Evaluation of this possibility will require a comprehensive characterization of embryonic expression sites, because we have determined that 3-OST-1 transcripts are expressed throughout all stages of embryonic development (HajMohammadi and Shworak, unpublished data). Moreover, complementation studies must be conducted to confirm that these phenotypes are directly dependent on 3-OST-1 deficiency.

\section{Acknowledgments}

We thank Jian Liu for the generous gift of recombinant 3-OST-1 enzyme. We are grateful to members of the R.D. Rosenberg and N.W. Shworak laboratories for their insightful comments. This work was supported in part by NIH grant PO1 HL41484-12 (R.D. Rosenberg), the Swiss National Foundation grant 32-59030.99 (M. Princivalle and A. de Agostini), the Carlos and Eslie De Reuter Foundation (M. Princivalle and A.I. de Agostini), the Human Frontier Science Program grant RG0304 (N.W. Shworak), the Department of Medicine, Beth Israel Deaconess Medical Center (N.W. Shworak), and the Department of Medicine, Dartmouth Medical School (N.W. Shworak).

1. Damus, P.S., Hicks, M., and Rosenberg, R.D. 1973. Anticoagulant action of heparin. Nature. 246:355-357.

2. Rosenberg, R.D., Shworak, N.W., Liu, J., Schwartz, J.J., and Zhang, L. 1997. Heparan sulfate proteoglycans of the cardiovascular system. Specific structures emerge but how is synthesis regulated? J. Clin. Invest. 99:2062-2070.

3. Rosenberg, R.D. 2001. Vascular-bed-specific hemostasis and hypercoagulable states: clinical utility of activation peptide assays in predicting thrombotic events in different clinical populations. Thromb. Haemost. 86:41-50.

4. Thomas, D.P., and Roberts, H.R. 1997. Hypercoagulability in venous and arterial thrombosis. Ann. Intern. Med. 126:638-644.

5. Hogan, K.A., Weiler, H., and Lord, S.T. 2002. Mouse models in coagulation. Thromb. Haemost. 87:563-574

6. van Boven, H.H., and Lane, D.A. 1997. Antithrombin and its inherited deficiency states. Semin. Hematol. 34:188-204.

7. Ishiguro, K., et al. 2000. Complete antithrombin deficiency in mice results in embryonic lethality. J. Clin. Invest. 106:873-878.

8. Marcum, J.A., and Rosenberg, R.D. 1989. The biochemistry, cell biology, and pathophysiology of anticoagulantly active heparin-like molecules of the vessel wall. In Heparin, chemical and biological properties: clinical applications. D.A. Lane and U. Lindahl, editors. Edward Arnold. London, United Kingdom. 275-294.
9. Shworak, N.W., et al. 1994. Pathway-specific regulation of the synthesis of anticoagulantly active heparan sulfate. J. Biol. Chem. 269:24941-24952.

10. Colliec-Jouault, S., Shworak, N.W., Liu, J., de Agostini, A.I., and Rosenberg, R.D. 1994. Characterization of a cell mutant specifically defective in the synthesis of anticoagulantly active heparan sulfate. J. Biol. Chem. 269:24953-24958.

11. Dewerchin, M., et al. 2001. Life-threatening thrombosis in mice with targeted Arg47 to Cys mutation of the heparin binding domain of antithrombin. 74th Scientific Sessions of the American Heart Association. Circulation. 104(Suppl. 2):109442. (Abstr.)

12. Bourin, M.C., Lundgren-Akerlund, E., and Lindahl, U. 1990. Isolation and characterization of the glycosaminoglycan component of rabbit thrombomodulin proteoglycan. J. Biol. Chem. 265:15424-15431.

13. Preissner, K.T., Delvos, U., and Muller-Berghaus, G. 1987. Binding of thrombin to thrombomodulin accelerates inhibition of the enzyme by antithrombin III. Evidence for a heparin-independent mechanism. Biochemistry. 26:2521-2528.

14. de Agostini, A.I., Watkins, S.C., Slater, H.S., Youssoufian, H., and Rosenberg, R.D. 1990. Localization of anticoagulantly active heparan sulfate proteoglycans in vascular endothelium: antithrombin binding on cultured endothelial cells and perfused rat aorta. J. Cell Biol. 111:1293-1304.

15. Xu, Y., and Slayter, H.S. 1994. Immunocytochemical localization of endogenous anti-thrombin III in the vasculature of rat tissues reveals locations of anticoagulantly active heparan sulfate proteoglycans. J. Histochem. Cytochem. 42:1365-1376.

16. Iozzo, R.V. 2001. Heparan sulfate proteoglycans: intricate molecules with intriguing functions. J. Clin. Invest. 108:165-167. doi:10.1172/JCI200113560.

17. Esko, J.D., and Lindahl, U. 2001. Molecular diversity of heparan sulfate. J. Clin. Invest. 108:169-173. doi:10.1172/JCI200113530.

18. Shworak, N.W., Fritze, L.M.S., Liu, J., Butler, L.D., and Rosenberg, R.D. 1996. Cell-free synthesis of anticoagulant heparan sulfate reveals a limiting activity which modifies a nonlimiting precursor pool. J. Biol. Chem. 271:27063-27071.

19. Liu, J., Shworak, N.W., Fritze, L.M.S., Edelberg, J.M., and Rosenberg, R.D. 1996. Purification of heparan sulfate D-glucosaminyl 3-O-sulfotransferase. J. Biol. Chem. 271:27072-27082.

20. Shworak, N.W., et al. 1997. Molecular cloning and expression of mouse and human cDNAs encoding heparan sulfate D-glucosaminyl 3-O-sulfotransferase. J. Biol. Chem. 272:28008-28019.

21. Zhang, L., et al. 2001. The effect of precursor structures on the action of glucosaminyl 3-O-sulfotransferase-1 and the biosynthesis of anticoagulant heparan sulfate. J. Biol. Chem. 276:28806-28813.

22. Shworak, N.W., et al. 1999. Multiple isoforms of heparan sulfate D-glucosaminyl 3-O-sulfotransferase. Isolation, characterization, and expression of human cDNAs and identification of distinct genomic loci. J. Biol. Chem. 274:5170-5184.

23. Liu, J., et al. 1999. Expression of heparan sulfate D-glucosaminyl 3-O-sulfotransferase isoforms reveals novel substrate specificities. J. Biol. Chem. 274:5185-5192.

24. Shukla, D., et al. 1999. A novel role for 3-O-sulfated heparan sulfate in herpes simplex virus 1 entry. Cell. 99:13-22.

25. Yabe, T., et al. 2001. Portable sulphotransferase domain determines sequence specificity of heparan sulphate 3-O-sulphotransferases. Biochem. J. 359:235-241.

26. Enjyoji, K., et al. 1999. Targeted disruption of cd39/ATP diphosphohydrolase results in disordered hemostasis and thromboregulation. Nat. Med. 5:1010-1017.

27. Bradford, M.M. 1976. A rapid and sensitive method for the quantitation of microgram quantities of protein utilizing the principle of protein-dye binding. Anal. Biochem. 72:248-254.

28. Björnsson, S. 1998. Quantitation of proteoglycans as glycosaminoglycans in biological fluids using an Alcian blue dot blot analysis. Anal. Biochem. 256:229-237.

29. Marcum, J.A., and Rosenberg, R.D. 1985. Heparinlike molecules with anticoagulant activity are synthesized by cultured endothelial cells. Biochem. Biophys. Res. Commun. 126:365-372.

30. de Agostini, A.I., Ramus, M.A., and Rosenberg, R.D. 1994. Differential partition of anticoagulant heparan sulfate proteoglycans synthesized by endothelial and fibroblastic cell lines. J. Cell. Biochem. 54:174-185.

31. Princivalle, M., Hasan, S., Hosseini, G., and de Agostini, A.I. 2001. Anticoagulant heparan sulfate proteoglycans expression in the rat ovary peaks in preovulatory granulosa cells. Glycobiology. 11:183-194.

32. Christie, P.D., et al. 1999. A murine model of myocardial microvascular thrombosis. J. Clin. Invest. 104:533-539.

33. Weiler-Guettler, H., et al. 1998. A targeted point mutation in thrombomodulin generates viable mice with a prethrombotic state. J. Clin. Invest. 101:1983-1991.

34. Weiler, H., et al. 2001. Characterization of a mouse model for thrombomodulin deficiency. Arterioscler. Thromb. Vasc. Biol. 21:1531-1537.

35. Chatterton, J.E., et al. 1999. Expression cloning of LDLB, a gene essential for normal Golgi function and assembly of the ldlCp complex. Proc. Natl. Acad. Sci. U. S.A. 96:915-920. 
36. Van Parijs, L., et al. 1999. Uncoupling IL-2 signals that regulate T cell proliferation, survival, and Fas-mediated activation-induced cell death. Immunity. 11:281-288.

37. Marcum, J.A., et al. 1986. Cloned bovine aortic endothelial cells synthesize anticoagulantly active heparan sulfate proteoglycan. J. Biol. Chem. 261:7507-7517.

38. Carlson, T.H., Atencio, A.C., and Simon, T.L. 1984. In vivo behavior of radioiodinated rabbit antithrombin III. Demonstration of a noncirculating vascular compartment. J. Clin. Invest. 74:191-199.

39. Lawson, C.A., et al. 1997. Monocytes and tissue factor promote thrombosis in a murine model of oxygen deprivation. J. Clin. Invest. 99:1729-1738

40. Konstantinides, S., Schafer, K., Koschnick, S., and Loskutoff, D.J. 2001. Leptin-dependent platelet aggregation and arterial thrombosis suggests a mechanism for atherothrombotic disease in obesity. J. Clin. Invest. 108:1533-1540. doi:10.1172/JCI200113143.

41. Ni, H., et al. 2001. Increased thrombogenesis and embolus formation in mice lacking glycoprotein V. Blood. 98:368-373.

42. He, L., Vicente, C.P., Westrick, R.J., Eitzman, D.T., and Tollefsen, D.M. 2002. Heparin cofactor II inhibits arterial thrombosis after endothelial injury. J. Clin. Invest. 109:213-219. doi:10.1172/JCI200213432.

43. Zhang, L., et al. 2001. 6-O-Sulfotransferase-1 represents a critical enzyme in the anticoagulant heparan sulfate biosynthetic pathway. J. Biol. Chem. 276:42311-42321.
44. Segel, G.B., and Francis, C.A. 2000. Anticoagulant proteins in childhood venous and arterial thrombosis: a review. Blood Cells Mol. Dis. 26:540-560.

45. Peeters, L.L. 2001. Thrombophilia and fetal growth restriction. Eur. J Obstet. Gynecol. Reprod. Biol. 95:202-205.

46. Lang, U., Baker, R.S., Khoury, J., and Clark, K.E. 2000. Effects of chronic reduction in uterine blood flow on fetal and placental growth in the sheep. Am. J. Physiol. Regul. Integr. Comp. Physiol. 279:R53-R59.

47. Lin, C.C., and Santolaya-Forgas, J. 1998. Current concepts of fetal growth restriction: part I. Causes, classification, and pathophysiology. Obstet. Gynecol. 92:1044-1055.

48. Dilmen, G., Toppare, M.F., Turhan, N.O., Ozturk, M., and Isik, S. 1996. Transverse cerebellar diameter and transverse cerebellar diameter/abdominal circumference index for assessing fetal growth. Fetal Diagn. Ther. 11:50-56.

49. Sugimura, M., Kobayashi, T., Shu, F., Kanayama, N., and Terao, T. 1999. Annexin V inhibits phosphatidylserine-induced intrauterine growth restriction in mice. Placenta. 20:555-560.

50. Kupferminc, M.J., et al. 1999. Increased frequency of genetic thrombophilia in women with complications of pregnancy. N. Engl. J. Med. 340:9-13.

51. Gandelman, R., and Simon, N.G. 1978. Spontaneous pup-killing by mice in response to large litters. Dev. Psychobiol. 11:235-241. 